Lutais, F. (1979) De ABV in de klinische situatie. (The ABV in clinical situations). Heymans Bulletins HB 79-412 EX, State University of Groningen. De Psycholoog, 14, 388-389.

\section{Is globus hystericus?}

SIR: The Journal Club at this hospital met recently to discuss 'Is globus hystericus?' by Wilson et al (Journal, September 1988, 153, 335-339). The exercise seemed to offer considerable educational rewards, which other readers may wish to share if they have not already done so. An initial difficulty was that the promisingly quizzical title of the piece obscured its evident lack of scientific objectives beyond "the use of psychological inventories in globus patients". Its potential value paled further as no adequate description was to be found of how the patients included in the study were selected for it, let alone of how they compared with co-attenders at the same department who were not. The reasons for choosing the instruments used, the GHQ and the EPI, were not given; the choice seemed inadequate for most purposes, given the well-known problems of interpretation of the former in the context of physical illness, and the lack of discriminatory value exhibited by the EPI in the only comparable psychological study of hysteria the authors quote. (The authors hardly increase confidence in their objectivity when they opine, in anticipation of criticism of the GHQ, that "we do not agree ... that most cases of globus have a physical basis"). The interpretations they place on their questionnaire findings, that they "support the inclusion of conversion disorder with dysthymic disorders", prompted much surprise, the study being notable for the absence of any specific measure of affective symptomatology, or any independent attempt at psychiatric diagnosis of its sample.

We appreciate that the publication of any study that fails, as this one does, to acknowledge related psychiatric research (e.g. previous studies of other discrete hysterical syndromes such as pseudoseizures), and whose own design is flawed, may inspire more satisfactory successors. However, our meeting did feel that the value of such a study is otherwise limited, and that it should not be taken as a model for others.

Chris Mace Maria RoN Martin Deahl RAY DOLAN JEREMY BIRD ANTHONY FEINSTEIN The National Hospitals for Nervous Diseases Queen Square London WCIN $3 B G$
SIR: How striking that six workers at the National Hospitals for Nervous Diseases (NHND) should take exception to one of the few empirical reports on the personalities of globus patients. We selected the Eysenck Personality Inventory, the best-known and best-validated personality test in Britain - long percieved by its author, Hans Eysenck, to distinguish individuals suffering from hysterical disorders. We reported simply that female globus patients were markedly neurotic and introverted and that our small sample of male patients were decisively low in emotionality.

The study had clear scientific objectives beyond the use of psychological questionnaires-indeed, these are stated in the first few lines of the abstract. The patients were investigated with a wide range of physical tests - radiology, haematology, endoscopy, and specialised tests of oesophagogastric function. That these were somehow overlooked by your correspondents from the NHND brings out an important point about globus pharyngis, namely that the background literature, current aetiological theories, and clinical experience of the condition are, with a few exceptions, confined to departments of otolaryngology.

The patients were diagnosed using the standard clinical criteria for globus, and they were consecutive attenders at the globus clinic in our ENT department. Otherwise they were unselected. We accept that the data from this exploratory psychological assessment, which was performed in conjunction with extensive physical investigations, would have benefited from the inclusion of an ENT control group. We were, however, able to compare our patients with matched British norms, such as are furnished currently by no other form of personality assessments, and to show an unexpected and interesting result.

Our statement of disbelief in the physical basis of globus was not a subjective opinion intended to deflect criticism of GHQ scores. Rather, it was our conclusion after the negative results of our extensive physical investigations. These are reported in the text and are, as also stated in the paper, published elsewhere.

We are criticised for suggesting, on the basis of the globus model, that conversion disorder be included within the dysthymic group. Readers beyond the first half sentence of this paragraph will see that the term dysthymic was used in the way that Eysenck has used it for over $\mathbf{4 0}$ years - to refer to a group of neurotic disorders where patients' personalities tend to be introverted and high on neuroticism. Nevertheless, the workers from NHND appear to be unaware of the finding that neuroticism scores are strongly 
predictive of mood fluctuations (particularly dysthymic swings) over time (Williams, 1981).

Our reference list (44 items) does contain recent reviews of conversion disorder and will be adequate for most readers of a publication of this nature. We stated on the first page of our text our reasons for considering globus to be different from disorders such as pseudoseizures.

It remains our opinion that globus might make a good model for conversion disorder. The results of our preliminary study have encouraged us to continue our study of psychological factors in globus. A report, in preparation, of a substantial number of patients, including an ENT control group, uses questionnaires designed to index psychoneurotic disorder and attempts to replicate our previous results on the personality traits of globus patients.

We agree with the workers from NHND that journal clubs can be educationally rewarding. Sometimes, however, the joint perusal of a document can lead to errors in understanding.

Otolaryngology Unit

The Royal Infirmary (Phase 1)

Edinburgh EH3 9EN

\section{Reference}

WiLliams, D. G. (1981) Personality and mood: state - trait relationships. Personality and Individual Differences, 2, 303-309.

\section{Hospital suicides}

SIR: During our psychiatric training, it has been our combined experience that when a patient commits suicide, the responsible team responds with a mixture of sorrow, guilt, embarrassment, and concern about possible litigation; there is little open discussion.

In our training, much attention is given to learning about known risk factors for suicide. However, despite an extensive literature, assessing suicide risk remains an imprecise art and virtually all psychiatrists recognise that despite their best efforts, some patients will successfully take their own lives.

It seems to us strange that emphasis is placed on learning about the theoretical aspects of assessment of suicidal risk, but that when a suicide does occur, the absence of ensuing discussion severely hampers the learning of practical lessons.

We believe that a completed suicide in a psychiatric patient is an extremely valuable opportunity from which lessons may be learnt for the benefit of future patients. It is our belief that formal discussion of such cases would have several benefits: firstly, and most importantly, it would help the responsible team and other staff to learn from the case: secondly, it would reduce unhelpful speculation; thirdly, if conducted sensitively, it would reduce, rather than increase, the anxieties of involved professionals; and fourthly, it could facilitate later discussion with bereaved relatives.

In medicine and surgery it is standard practice to hold post-mortem review of 'difficult' cases, with formal discussions of findings in the light of clinical presentation and interventions. We are not aware of this practice in psychiatry, but would be keen to learn of its existence and of the opinions of those who have experienced it.

\section{Charles Burns Clinic \\ Queensbridge Road \\ Moseley \\ Birmingham BI3 $8 Q B$}

MarCellino SMYTH Nick CRADDOCK

SIR: Goh et al (Journal, February 1989, 154, 247-249) draw attention to the special features of suicide by psychiatric day and in-patients, and highlighted the importance of factors that related not only to the patient's illness but also to the immediate ward environment. Using the Edinburgh Suicide Case Register, I recently identified and reviewed the case notes of psychiatric in-patients who committed suicide in the Royal Edinburgh Hospital between 1977 and 1985. There were 29 such cases, and this population shared many of the characteristics of that described by Goh et al. However, in the Edinburgh survey there was an increased proportion of females, and the diagnoses of neurosis, personality disorder, and adjustment reaction were more common than in the Birmingham study. Also, over half had a past history of deliberate self-harm.

The notion of the high-risk patient can be described with reference to the characteristics of those who complete suicide, but it is more difficult to predict from patient characteristics which ones actually go on to commit suicide. Pokorny (1983) identified patient characteristics on admission in an attempt to predict which ones would later kill themselves, without success. Thus, it is particularly relevant to consider what local environmental factors influence suicide, as such factors may lend themselves more liable to change. Local ward layout is of obvious importance - such as the types of windows, window locks, and bathroom arrangements. In the Edinburgh study, means of suicide ranged from hanging by a bathrobe cord in the ward toilet area to jumping off the Forth Road Bridge. 